Laporan Kasus

\title{
Sindrom kanalis semisirkularis superior
}

\author{
Haris Mayagung Ekorini \\ Departemen Ilmu Kesehatan Telinga Hidung Tenggorok Bedah Kepala dan Leher \\ Fakultas Kedokteran Universitas Airlangga \\ Rumah Sakit Dr. Soetomo Surabaya
}

\begin{abstract}
ABSTRAK
Latar belakang: Sindrom kanalis semisirkularis superior (superior semicircular canal dehiscence syndrome) adalah suatu kelainan yang sangat jarang ditemukan. Terjadi gangguan keseimbangan atau vertigo yang dipicu oleh suara keras atau tekanan. Keadaan ini disebabkan karena terjadi dehisensi di daerah os tulang temporal pada kanalis semisirkularis superior, sehingga menjadi jendela ketiga (third window). Gejala klinis dari sindrom kanalis semisirkularis superior (SKSS) adalah autofonia, yaitu suara yang ditimbulkan oleh tubuhnya terdengar lebih keras, hiperakusis, tinitus, vertigo yang dipicu oleh suara keras dan dapat terjadi nistagmus. Diagnosis ditegakkan dengan anamnesis yang cermat, pemeriksaan pendengaran dan keseimbangan serta dilakukan CT scan resolusi tinggi. Penanganan dapat dilakukan dengan operasi atau konservatif. Tujuan: Agar para ahli THT dan dokter umum mengenal sindrom yang jarang ini. Kasus: Dilaporkan satu kasus penderita yang didiagnosis sebagai SKSS. Penderita mengeluh vertigo apabila mendengar suara keras, saat naik pesawat udara, telinga terasa penuh, bila berjalan dapat mendengar langkahnya dan tinitus. Dari pemeriksaan audiometri didapatkan tuli sensorineural ringan, timpanometri dan pemeriksaan keseimbangan sederhana tidak didapatkan kelainan, saat valsava didapatkan nistagmus dilihat dengan kacamata frenzel. Hasil CT scan resolusi tinggi didapatkan dehisensi pada kanalis semisirkularis superior kanan. Penatalaksanaan: Pada penderita ini belum dilakukan operasi tetapi dianjurkan menghindari suara keras dan menghindari perubahan tekanan misal menyelam, mengangkat benda berat, valsava. Kesimpulan: SKSS merupakan suatu kasus yang jarang, yang memerlukan anamnesis dan pemeriksaan yang cermat untuk menegakkan diagnosis penyakit ini.
\end{abstract}

Kata kunci: sindrom kanalis semisirkularis superior, vertigo, bising, tekanan

\section{ABSTRACT}

Background: Superior semicircular canal dehiscence syndrome (SSCD) is a very rare medical condition in which disturbances of balance or vertigo is triggered by loud noise or pressure. This condition is caused by dehiscence of a portion of the temporal bone overlying the superior semicircular canal and may present as the third window. Symptoms of the SCDS are autophony, which the person's own voice is loudly heard, hyperacusis, tinnitus, vertigo and nystagmus. Diagnosis is made by history, hearing and vestibular examinations, and high resolution CT scan. Its management includes surgery or conservatively. Purpose: To inform ENT specialists and general practitioners about this syndrome. Case: Reported one patient who was diagnosed as SCDS. The patient complain of vertigo when hearing a loud noise or while on an aeroplane, aural fullness, hearing his own footsteps while walking and tinnitus. The audiometric examination showed mild sensory-neural hearing loss, tympanometric and vestibular examination was nomal and nystagmus was found, observed by frenzel in valsava condition. The high resolution CT scan showed dehiscence on the roof of the right superior semicircular canal. Case management: Patient was given advice to avoid loud noise, air pressure changed such as diving, straining and valsava maneuver. 
Conclusion: SCDS is a rare medical condition, which needs accurate history taking and examination to establish the diagnosis.

Keywords: Superior canal dehiscence syndrome, vertigo, autophony

Alamat korespondensi: Haris M Ekorini. Dep/SMF Ilmu Kesehatan THT-KL Fakultas Kedokteran Unair- RSUD Dr. Soetomo. Jl. Mayjen Prof. Dr. Moestopo No. 6-8 Surabaya.

\section{PENDAHULUAN}

Sindrom kanalis semisirkularis superior (SKSS) atau superior canal dehiscence syndrome adalah suatu kelainan yang jarang ditemukan di mana terjadi gangguan keseimbangan atau vertigo yang dipicu oleh suara keras atau tekanan. SKSS ini pertama kali didiskripsikan oleh Lloyd Minor pada tahun 1998 setelah lebih dari 70 tahun sejak Tullio dan Hennebert menemukan kondisi di mana vertigo atau nistagmus yang dipicu oleh suara keras dan perubahan tekanan. Fenomena Tullio adalah vertigo atau nistagmus dipicu oleh suara keras yang dicurigai ada hubungan dengan sipilis, fistula perilimfatik, penyakit Meniere, trauma kepala, penyakit Lyme dan fistula labirin karena kolesteatoma. Tanda Hennebert yaitu vertigo atau nistagmus yang dipicu oleh perubahan tekanan. ${ }^{1,2}$ Pada tahun 1998 Minor menemukan seorang penderita yang mengalami defek pada kanalis semisirkularis superior mempunyai gejala fenomena Tulio dan tanda Hennebert. Teori Minor mengatakan apabila terjadi dehisensi dari bagian kanalis semisirkularis superior, maka akan menjadi jendela ketiga (third window), sehingga apabila terjadi perubahan tekanan atau suara keras akan merangsang aktivitas vestibuler. Gejala klinis dari SKSS ini disebabkan karena dehisensinya sehingga penderita akan mengeluh adanya autofonia yaitu suara yang ditimbulkan oleh tubuhnya terdengar lebih keras, hiperakusis, tinitus, vertigo yang dipicu oleh suara keras dan dapat terjadi nistagmus. Diagnosis ditegakkan berdasarkan anamnesis yang cermat, pemeriksaan pendengaran dan keseimbangan serta dilakukan CT scan resolusi tinggi. ${ }^{1-3}$

Laporan kasus ini disampaikan agar kelainan ini dapat diketahui oleh para ahli THT dan dokter umum.

\section{LAPORAN KASUS}

Seorang laki-laki usia 53 tahun datang ke poli Audiologi pada tanggal 15 Februari 2010 dengan keluhan vertigo. Vertigo dirasakan sejak empat tahun yang lalu, timbul bila mendengar suara keras dari sisi kanan. Bila mendengar bunyi klakson saat mobil disusul dari sisi kanan terasa seperti berputar, bila mendengar bunyi kompresor (saat menguras oli) juga terasa vertigo dan nyeri pada telinga, saat naik pesawat terasa nyeri dan vertigo, saat berjalan terasa telinga seperti ada airnya dan mendengar dung-dung di kepala sisi kanan (autofonia), vertigo tidak dipicu oleh perubahan posisi. Didapatkan tinitus sejak dua tahun yang lalu pada sisi kanan, bila mendengar suara keras terasa nyeri (hiperakusis). Tidak ada pajanan bising akibat kerja, penurunan pendengaran, trauma kepala dan riwayat menyelam. Riwayat hipertensi, diabetes mellitus dan kolesterol tinggi disangkal. Penderita tidak minum obat-obatan dalam jangka panjang.

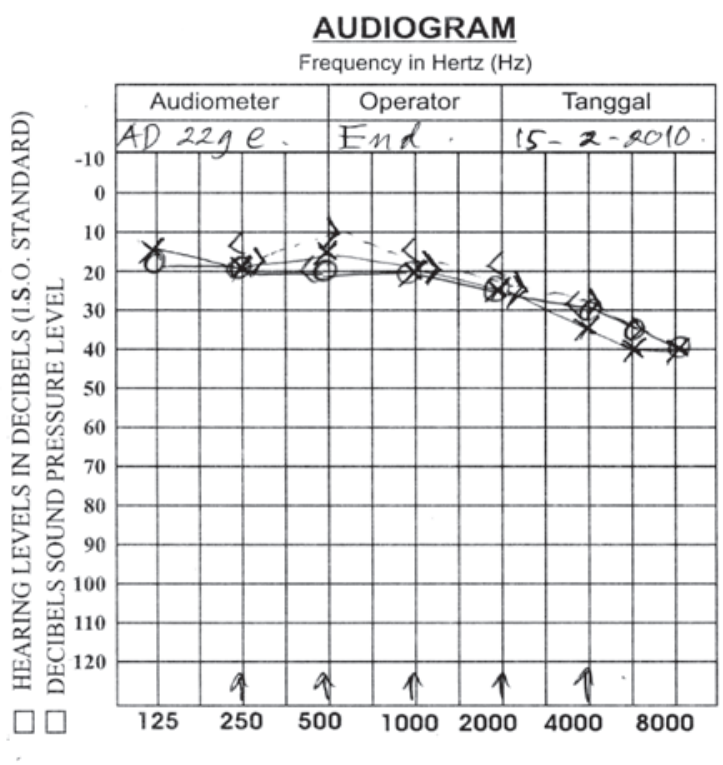

Gambar 1. Hasil audiogram 
Pada pemeriksaan fisik THT tidak didapatkan kelainan. Hasil audiogram memperlihatkan tuli sensorineural, dengan timpanogram tipe $\mathrm{A} / \mathrm{A}$, reflek akustik $+/+$.

Pemeriksaan keseimbangan Romberg/ Romberg dipertajam dan stepping test negatif. Gans performance normal. Head thrust, head shake dan Dix Hallpike negatif. Pada saat tes valsava didapatkan kesan adanya nistagmus. Timpanometri dengan stimulus 105-110 dB didapatkan kesan adanya nistagmus (observasi dengan kacamata Frenzel). CT scan os temporal tanpa kontras memperlihatkan defek tulang pada daerah kanalis semisirkularis superior, sedangkan sisi kiri masih tampak struktur tulang pada daerah kanalis semisirkularis superior. Kanalis semisirkularis lateral dan posterior tidak terlihat dehisensi. Koklea bilateral normal, tidak ada otosklerosis.

Penanganan penderita saat ini belum dilakukan intervensi operasi tetapi disarankan menghindari: suara keras, mengangkat beban berat, naik lift dengan kecepatan tinggi dan apabila naik pesawat diberi tetes hidung dulu.

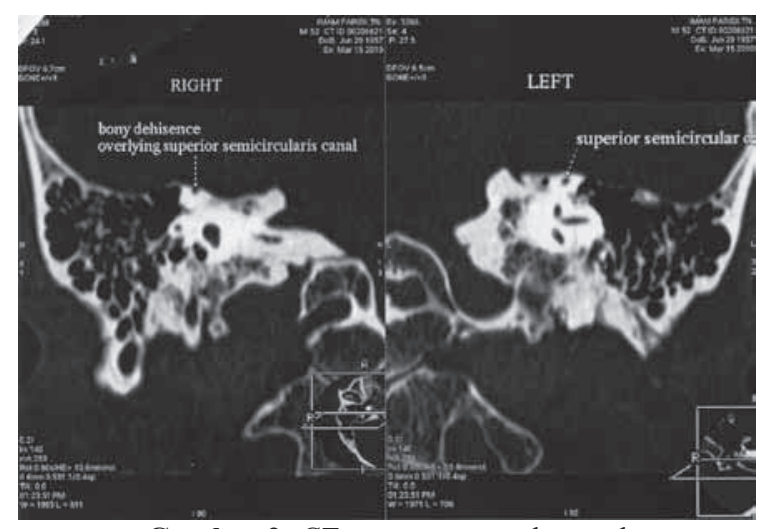

Gambar 2. CT scan potongan koronal

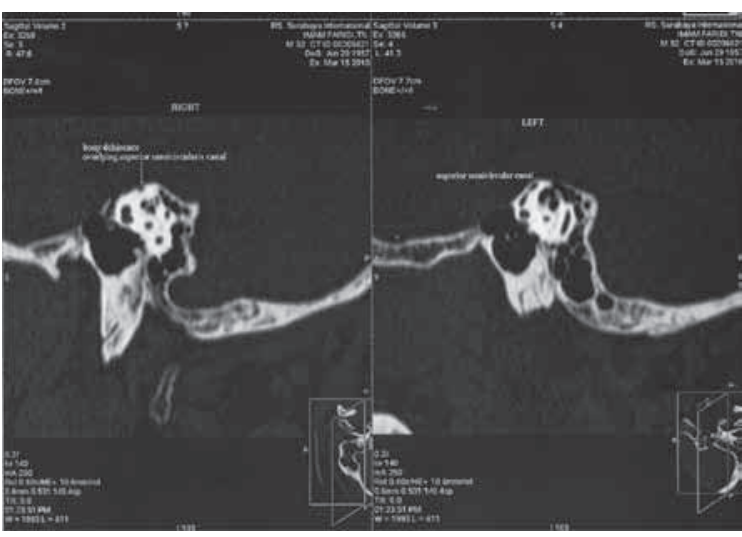

Gambar 3. CT scan potongan sagital

\section{DISKUSI}

Sindrom kanalis semisirkularis superior adalah suatu kelainan di mana terjadi dehisensi atap kanalis semisirkularis superior. Gejala yang timbul melibatkan masalah pendengaran dan keseimbangan. Secara umum gejala yang timbul dibagi menjadi dua yaitu yang berhubungan dengan suara dan perubahan tekanan. Gejala yang berhubungan dengan suara yaitu vertigo yang dipicu oleh suara keras (fenomena Tullio), autofonia (dapat mendengar suara dari tubuhnya sendiri), hiperakusis, telinga terasa penuh, tinitus, tuli konduksi frekuensi rendah, sedangkan gejala yang berhubungan dengan perubahan tekanan, yaitu vertigo bila tekanan intrakranial meningkat (tanda Hennebert) misal saat batuk, valsava, serta mengangkat benda berat. ${ }^{4-6}$ Penelitian yang dilakukan tahun 1999-2005 mendapatkan sebanyak 97\% penderita SKSS mengeluh vertigo yang dipicu suara keras, vertigo yang dipicu perubahan tekanan pada telinga tengah sebanyak $82 \%$, hiperakusis didapatkan pada $39 \%$ penderita. ${ }^{6}$ Peneliti lain melaporkan sebanyak 30 penderita didiagnosis sebagai SKSS sejak tahun 1999-2004. Dari 30 penderita tersebut sebanyak $63 \%$ mengalami gangguan keseimbangan kronik, $41 \%$ fenomena Tullio, 44\% vertigo yang dipicu oleh perubahan tekanan, penurunan pendengaran sebanyak 30\% dan tinitus sebanyak $7 \%{ }^{7}$

Patofisiologi adalah sebagai berikut, sistem kokleovestibuler mempunyai dua jendela, yaitu foramen rotundum dan foramen ovale. Foramen ovale yang langsung berhubungan dengan basis stapes akan menggerakkan perilimf skala vestibuli apabila ada gelombang suara, getaran diteruskan melalui membran Reissner mendorong endolimf dan membran basalis ke arah bawah, perilimf skala timpani akan bergerak sehingga foramen rotundum terdorong ke arah luar. Foramen ovale dan rotundum ini bekerja sama untuk mengatur pendengaran dan keseimbangan. Apabila terjadi dehisens pada kanalis semisirkularis superior, maka akan terdapat jendela ketiga yang akan ikut berperan. Akibatnya endolimf di dalam labirin akan meneruskan gerakan gelombang, sehingga menyebabkan aktivasi sistem vestibuler. ${ }^{1,8}$ 


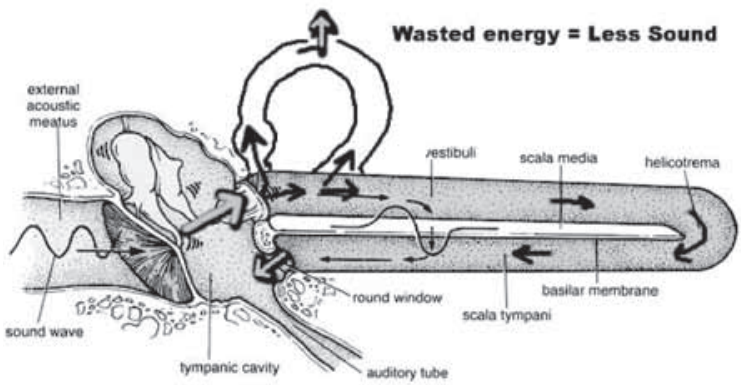

Gambar 4. Skema pada SCDS. ${ }^{9}$

Pada gambar 4 diibaratkan koklea adalah suatu ruang panjang dengan dua pintu masuk dan keluar. Bila pintu masuk penuh dengan orang kemudian banyak orang masuk, maka sebagian orang yang di dalam akan terdorong keluar. Pergerakan inilah yang dideteksi sebagai suara. Sebaliknya organ keseimbangan merupakan sistem yang tertutup diibaratkan seperti arena balap, pergerakan dari cairan (analoginya seperti orang di dalam ruang panjang) di dalam ruang tertutup tadi dideteksi sebagai pergerakan kepala. Bila organ keseimbangan ini utuh, maka fungsi pendengaran dan keseimbangan tidak tergantung satu sama lainnya, tetapi bila terdapat pintu ketiga pada organ keseimbangan, maka cairan dapat berpindah dan akan memgurangi kepadatan di koklea sehingga sensasi suara berkurang. Kondisi ini akan menambah kecepatan cairan di organ keseimbangan yang menyebabkan keluhan vertigo. ${ }^{9}$

Mengapa terjadi dehisensi? Pada saat lahir, tulang dengan tebal sekitar $0,1 \mathrm{~mm}$ memisahkan kanalis semisirkularis dari duramater yang menutupi lobus temporalis dan tulang ini akan bertambah tebal sampai $1 \mathrm{~mm}$ pada umur 3 tahun. Sekitar 1-2\% dari populasi, tulang tidak bertambah tebal, bahkan akan menipis dengan bertambahnya umur, bila ketebalan kurang dari 0,5 mm maka cellophane (lapisan tulang) yang tipis ini mudah pecah karena trauma. Mengapa terjadi erosi tulang atau erosi lambat sampai saat ini belum dapat diterangkan. Kondisi ini juga dapat terjadi karena kelainan kongenital. ${ }^{4,5}$

Penderita SKSS akan mempunyai gejalagejala seperti di atas. Gejala yang timbul dapat berlangsung sepanjang waktu atau mendadak

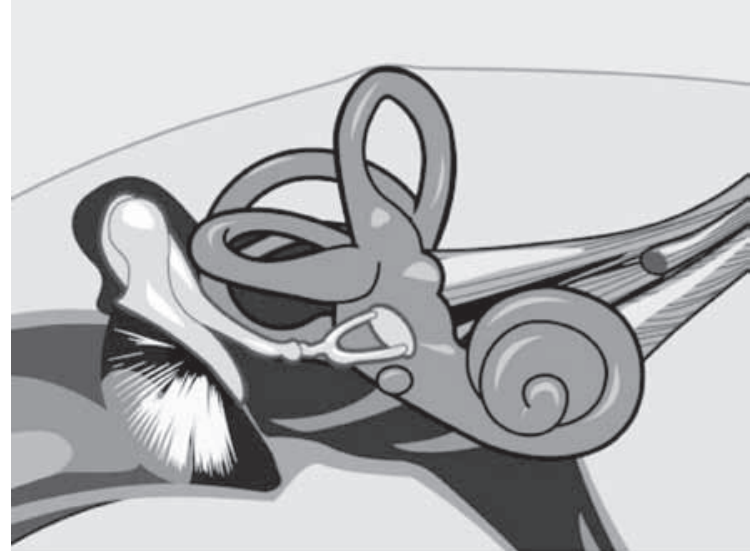

Gambar 5. Kanalis semisirkularis superior dengan lapisan tulang yang tipis. ${ }^{5}$

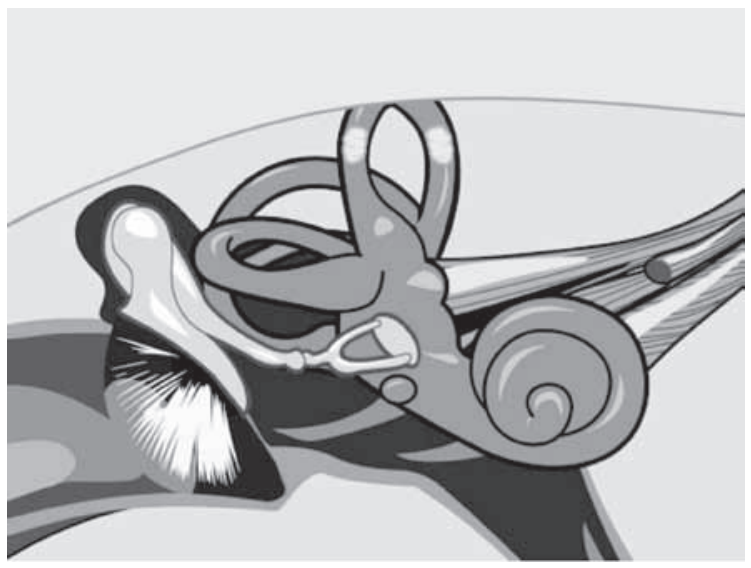

Gambar 6. Dehisensi kanalis semisirkularis superior. ${ }^{5}$

yang disebabkan oleh trauma telinga, suara keras atau perubahan tekanan. Terdapat kecenderungan bahwa gejala akan bertambah berat setelah gejala pertama muncul. Gejala yang timbul dapat berlangsung sampai 10-15 tahun sebelum gejala yang berat muncul, sehingga penderita mencari pengobatan. Dilaporkan penderita termuda yang ditemukan berumur 29 tahun dan tertua 82 tahun dengan rata-rata umur 50 tahun. ${ }^{5}$ Pada kasus ini penderita ditemukan saat berumur 53 tahun dengan keluhan sejak 4 tahun yang lalu.

Gejala autofonia yaitu penderita dapat mendengar suara yang berasal dari tubuhnya sendiri (misal detak jantung, saat mengunyah, saat berjalan mendengar suara langkahnya). Pada kasus ini penderita ini dapat mendengar suara langkahnya sendiri pada sisi kanan. Autofonia pada SKSS berbeda dengan yang terjadi pada tuba yang terbuka yaitu patulous tuba Eustachius di mana penderita dapat mendengar suara 
napas dan bicaranya sendiri. Sebaliknya pada penderita SKSS autofonia dilaporkan suara yang terdengar dari tubuhnya sangat mengganggu seperti loudspeaker yang pecah. Penderita dapat mendengar suara persendiannya yang bergerak, suara langkah saat berjalan atau berlari dan saat mengunyah. Pada beberapa penderita keadaan ini sangat mengganggu disebut sebagai hiperakusis, seperti digambarkan andaikata garpu tala digetarkan dan diletakkan pada tungkai, maka penderita dapat mendengar pada sisi yang sakit. ${ }^{4,8}$ Peneliti lain melaporkan seorang penderita yang mengeluh telinga terasa penuh dan seperti terbuntu, vertigo yang intermiten dengan pemicu saat tertawa, batuk, bersin atau suara keras, naik tangga dan mengangkat benda berat di mana di antara periode tersebut tidak ada keluhan vertigo. ${ }^{10}$ Dilaporkan 3 orang penderita SKSS dengan keluhan yang sama ${ }^{11}$, sedangkan peneliti lain melaporkan sejak Januari 2005-Oktober 2007 sebanyak 19 penderita didiagnosis sebagai SKSS juga mempunyai keluhan autofonia. ${ }^{12}$

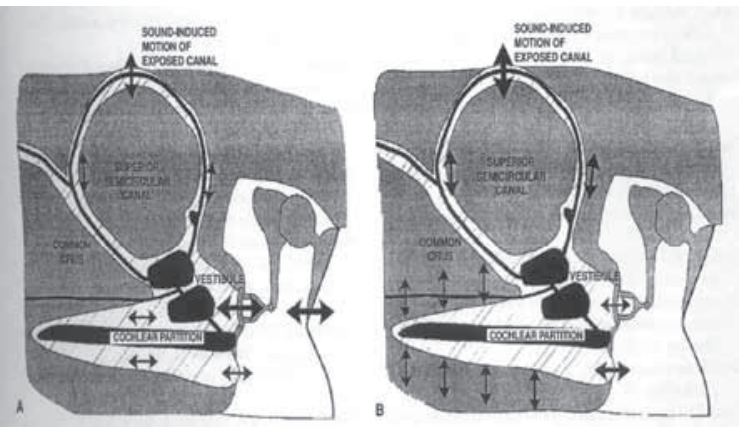

Gambar 7. Skema pada SCDS. ${ }^{13}$

Dari hasil pemeriksaan audiometri didapatkan hasil tuli sensorineural ringan pada kedua sisi. Hal ini kurang sesuai dengan kepustakaan di mana pada SKSS didapatkan tuli konduksi. Evaluasi audiometri dilakukan pada semua penderita vertigo. Pada SKSS, gangguan pendengaran biasanya tuli konduksi pada frekuensi rendah di bawah $1 \mathrm{kHz}$. Tuli konduksi ini terjadi akibat adanya jendela ketiga dari kanalis semisirkularis superior, menyebabkan peningkatan ambang dengar hantaran udara. ${ }^{1,13}$

Gambar 7 menunjukkan hantaran udara (A). Energi suara yang masuk ke koklea melalui foramen ovale sebagian akan menuju kanalis semisirkularis yang dehisensi, sehingga berdampak peningkatan ambang dengar hantaran udara. Gambar ini juga menunjukkan hantaran tulang (B), dari kedua gambar ini mengakibatkan adanya air-bone gap tanpa ada patologi di telinga tengah. ${ }^{13}$

Pemeriksaan timpanometri pada kasus ini didapatkan refleks akustik kanan kiri karena gangguan pendengaran adalah sensorineural ringan kanan kiri. Kepustakaan menyebutkan bahwa pada SKSS refleks akustik muncul walaupun terdapat tuli konduksi, keadaan ini berbeda dengan otosklerosis yang merupakan diagnosis bandingnya di mana refleks akustik tidak muncul. ${ }^{1,14}$

Hasil pemeriksaan keseimbangan sederhana pada kasus ini tidak didapatkan kelainan, kemudian saat dilakukan tes valsava didapatkan nistagmus, dan pada pemeriksaan timpanometri dengan stimulus 105-110 dB kesan nistagmus juga positif. Kepustakaan menyebutkan tes Gait, Romberg, Stepping, Dix Hallpike, Head shake dan Head thrust pada SKSS tidak ada kelainan, sedangkan pemeriksaan dengan stimulus 100-110 dB pada frekuensi $500-2000 \mathrm{~Hz}$ akan menunjukkan nistagmus vertikal dan torsional. Pemeriksaan fistula didapatkan nistagmus vertikal dan torsional dengan fase lambat menjauh dari sisi sakit, tetapi pada pemeriksaan dengan valsava menunjukkan nistagmus ke arah sebaliknya. ${ }^{1,15-18}$ Pemeriksaan elektronistagmografi (ENG) dapat membantu diagnosis SKSS di mana terjadi nistagmus waktu dilakukan timpanometri dan valsava. ${ }^{76,18}$ Pada kasus ini juga terdapat nistagmus waktu dilakukan pemeriksaan timpanometri dan valsava, walaupun tidak dapat direkam dengan baik karena tidak adanya alat ENG.

Pemeriksaan radiologi dengan $C T$ scan resolusi tinggi sangat penting untuk menegakkan diagnosis SKSS, pada kasus ini didapatkan defek tulang pada daerah kanalis semisirkularis superior kanan dengan irisan 0,6 mm potongan koronal dan aksial yang menyokong adanya dehisensi kanal superior dekstra. Peneliti lain mengatakan dari 17 operasi yang dilakukan, 16 terdapat fistula pada 
telinga yang dicurigai dan 1 operasi hanya terdapat blue line (garis biru). Pada satu penderita ini hasil CT scan hanya menunjukkan dehisensi pada 1 irisan saja. Dengan adanya positif palsu ini, maka kriteria diagnostik diputuskan apabila terdapat dehisensi pada 2 irisan $1 \mathrm{~mm}$. CT scan irisan $1 \mathrm{~mm}$ mempunyai nilai prediksi positif hanya $50 \%$ pada semua populasi. Oleh karenanya untuk menentukan diagnostik diperlukan anamnesis yang cermat, gejala klinis yang jelas, pemeriksaan audiometri dan vestibuler serta $C T s c$ an resolusi tinggi di mana pada 2 irisan tampak dehisensi. CT scan irisan 0,6 $\mathrm{mm}$ dengan potongan koronal memberikan hasil yang lebih baik. ${ }^{3,7}$

Penanganan penderita SKSS dapat dilakukan secara konservatif atau dengan operatif Penanganan konservatif dilakukan dengan cara menghindari: mengangkat benda berat, membungkuk, ketegangan jiwa, perubahan tekanan udara misal saat perjalanan udara, naik lift berkecepatan tinggi, menyelam, meniup keras, suara keras. Pipa ventilasi (Grommet) dapat membantu mengurangi perubahan tekanan udara di telinga tengah. ${ }^{3}$ Pada kasus ini penanganan dilakukan secara konservatif. Peneliti lain mengatakan banyak penderita hanya terdapat keluhan ringan, sehingga tidak memerlukan penanganan operatif, ${ }^{5}$ sedangkan penelitian retrospektif yang dilakukan tahun 1999-2004 mengatakan bahwa $48 \%$ dari 30 penderita yang datang ke institusinya tidak memerlukan pembedahan karena hanya mempunyai keluhan ringan. ${ }^{7}$ Apabila keluhan tidak mengganggu dilakukan terapi konservatif, tetapi bila sangat mengganggu dilakukan terapi operatif. ${ }^{4}$

Terapi operatif untuk SKSS saat ini masih dikembangkan dengan inovasi baru..$^{1,10,20,21}$ Terapi operatif dapat dilakukan dengan dua cara yaitu pertama menutup/melapisi dehisensi kanal (superior canal resurfacing) dan yang kedua dengan membuntu kanal (canal plugging). Material yang digunakan untuk melapisi adalah jaringan lunak, tulang, bahan surgikal, sedangkan untuk membuntu dapat digunakan bubuk tulang dan fasia.

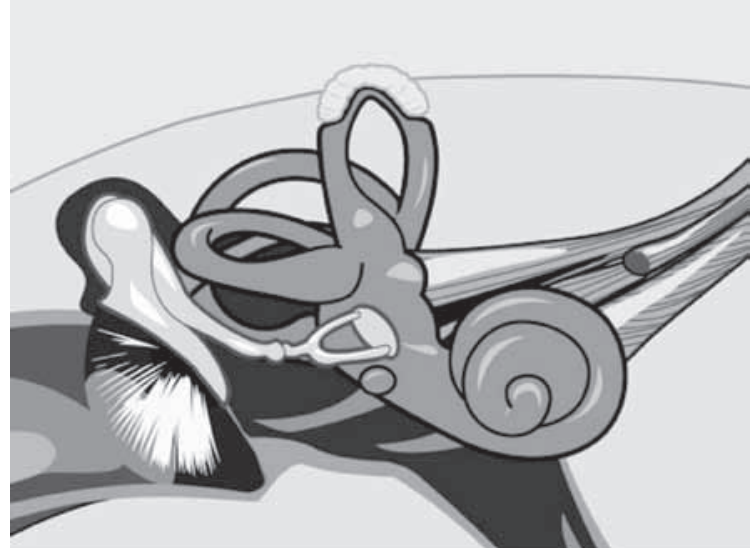

Gambar 8. Superior canal resurfacing. ${ }^{5}$

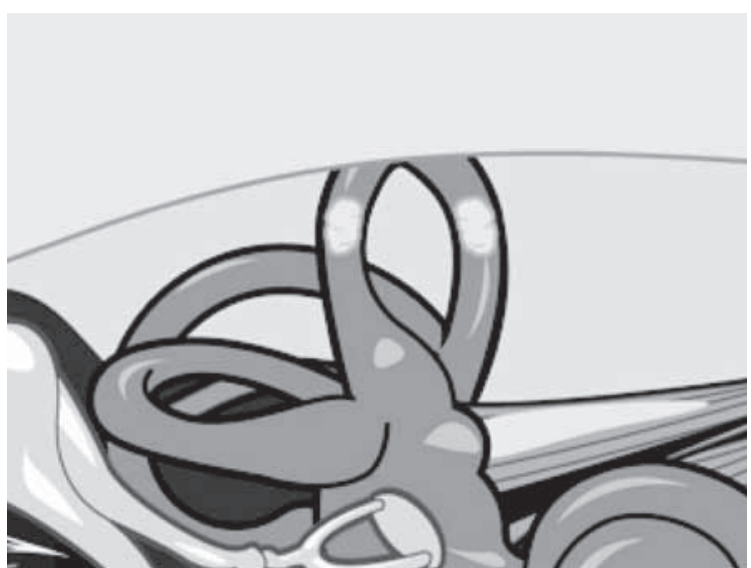

Gambar 9. Canal plugging.
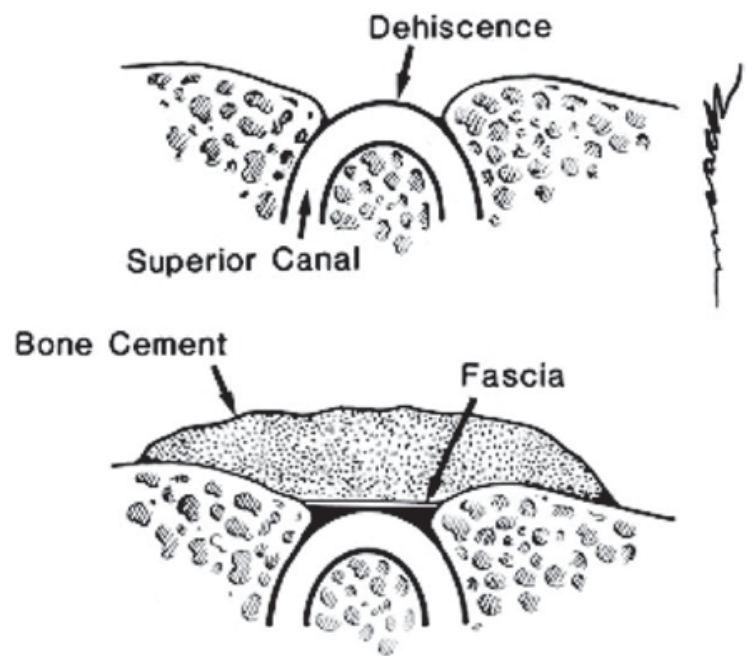

Gambar 10. Dehisensi ditutup dengan fascia yang dilapisi dengan bone cement. ${ }^{7}$

Sebagai kesimpulan, diperlukan anmanesis yang cermat dan pemeriksaan yang teliti untuk menegakkan diagnosis SKSS yang sangat jarang ditemukan. Penatalaksanaannya secara konservatif dahulu, bila keluhan berat dipertimbangkan operasi. 


\section{DAFTAR PUSTAKA}

1. Shaia WT, Kartusin JM, Peng AS. Superior canal dehiscence. Available from: http://emedicine.medscape. com/article/857914-overview. Accessed March 10, 2010.

2. Hain TC. Tullio's Phenomenon. Available from: http:// www.dizzines-and-balance.com/disorde/symptoms/ tullio.html. Accessed March 10, 2010.

3. Hain TC. superior canal dehiscence. Available from http://www.dizzines-and-balance.com/disorder/unilat/ scd.htm. Accessed March 26, 2010.

4. Superior canal dehiscence. Available from: http:// en.wikipedia.org/wiki/superior_canal_dehiscence. Accessed March 10, 2010.

5. Teixido M. Superior canal dehiscence syndrome. Available from: http://www.dbi.udel.edu/MichaelTeixidoMD/ patientInfo/SCDS.htm. Accessed April 12, 2010.

6. Minor LB. Clinical Manifestations of superior semicircular canal dehiscence. Laryngoscope 2005; 115: 1717-27.

7. Hillman TA, Kertesz TR, Hadley K, Shelton C. Reversible peripheral vestibulopathy: the treatment of superior canal dehiscence. Otolaryngol-Head Neck Surg 2006; 134:431-6.

8. Mong A, Loevner LA, Solomon D, Bigelow DC. Sound and pressure-induced vertigo associated with dehiscence of the roof of the superior semisircular canal. Am J Neuroradiol 1999; 20:1937-5.

9. Anonymous. Superior canal dehiscence syndrome. Available from: http://dr-li.net/SCD.htm. Accessed April 15, 2010.

10. Wilkinson EP, Liu GC, Friedman RA. Correction of progressive hearing loss in superior canal dehiscence syndrome. Laryngoscope 2008; 118:10-3.

11. Deschenes GR, Hsu DP, Megerian CA. Outpatient repair of superior semisircular canal dehiscence via the transmastoid approach. Laryngoscope 2008; 119:1765-9.

12. Crane BT, Minor LB, Carey JP. Superior canal dehiscence plugging reduces dizzines handicap. Laryngoscope 2008; 118:1809-13.
13. Vento BA, Durrant JD. Assesing bone conduction thresholds in clinical practice. In: Katz J, Medwetsky L, Burkard R, Hood LJ, eds. Handbook of clinical audiology. $6^{\text {th }}$ ed. Philadelphia: Lippincott Williams \& Wilkins; 2009. p. 50-62.

14. Merchant SN, Rosowski JJ, McKenna MJ. Superior semisircular dehiscence mimicking otosclerotic hearing loss. Available from: http://www.ncbinlm.nih. gov/pmc/articles/PMC2636720/. Accessed April 15, 2010.

15. Hullar TE, Minor LB. Vestibular physiology and disorder of the labyrinth. In: Glasscock ME, Gulya AJ, eds. Glasscock - Shambaugh surgery of the ear. $5^{\text {th }}$ ed. Hamilton, Ontario: BC Decker Inc, 2003. p. 83-101.

16. Isaacson J, Ort SA, Rubin A. Performing the physical examination: detecting spontaneous and gaze-evoked nystagmus. In: Goebel JA, ed. Practical management of the dizzy patient. $2^{\text {nd }}$ ed. Philadelphia: Lippincott Williams \& Wilkins; 2008. p. 61-73.

17. Carey JP, Minor LB. Disorder that affect central and peripheral vestibular fuction. In: Goebel JA, ed. Practical management of the dizzy patient. $2^{\text {nd }}$ ed. Philadelphia: Lippincott Williams \& Wilkins; 2008. p. 265-80.

18. Brandt T, Dieterich M, Strupp M. Peripheral vestibular forms of vertigo. In: Brandt T, Dieterich M, Strupp M, eds. Vertigo and dizzines. London: Springer-Verlag; 2005. p. 41-87.

19. Anonymous. Superior canal dehiscence syndrome lectures notes. Available from: http://dr-li.net/superior canal_dehiscence syndro.htm. Accessed April 15, 2010.

20. Vrabec JT. Surgical management of vestibular disorder. In: Bailey BJ, Johnson JT, Newlands SD, eds. Head and neck surgery otolaryngology. $4^{\text {th }}$ ed. Vol 2. Philadelphia: Lippincott Williams \& Wilkins; 2006. p. 2338-40.

21. Wackym PA. Therapy: Surgical alternative. In: Goebel JA, ed. Practical management of the dizzy patient. $2^{\text {nd }}$ ed. Philadelphia: Lippincott Williams \& Wilkins; 2008. p. 365-77. 